\title{
Análise do processo de formação profissional relacionado à docência em centros e
}

\section{escolas de beleza}

\author{
Analysis of the process of professional training related to teaching in beauty centers and schools \\ Análisis del proceso de formación profesional relacionado con la enseñanza en centros y escuelas de
}

belleza

Recebido: 12/07/2021 | Revisado: 17/07/2021 | Aceito: 18/07/2021 | Publicado: 26/07/2021

\author{
Anderson de Oliveira Firmino \\ ORCID: https://orcid.org/0000-0002-0553-8577 \\ Serviço Nacional de Aprendizagem, Brasil \\ E-mail: onimrif@hotmail.com \\ José Olímpio Ferreira Neto \\ ORCID: https://orcid.org/0000-0002-7258-467X \\ Secretaria Municipal de Educação de Fortaleza, Brasil \\ E-mail: jolimpioneto@hotmail.com
}

\begin{abstract}
Resumo
O presente artigo tem o objetivo de analisar o processo de formação profissional relacionado à docência em centros e escolas de beleza. Para alcançar esse objetivo, foi desenvolvida uma pesquisa de natureza qualitativa que consistiu, inicialmente, na abordagem de conceitos como beleza e estética atinentes ao campo profissional. Além disso, a formação do profissional foi abordada nos distintos níveis de ensino, a saber: básico e superior. Para isso, a pesquisa bibliográfica exploratória foi fundamental para dar subsídios na elaboração do quadro teórico deste trabalho. Partiu-se da hipótese de que para uma formação sólida na área da beleza é preciso alinhar o posicionamento de ensino referente ao grau técnico utilizado ou direcionado sobre a identificação do potencial de cada indivíduo, respeitando seu posicionamento, experiências, vivências, particularidades e aplicabilidade de técnicas referentes aos serviços prestados. Por fim, também foi apresentado, sob orientação etnográfica, a partir de vivência formativa de um dos signatários desta pesquisa como aluno e como instrutor na área da beleza, relatos autobiográficos para corroborar a necessidade de uma formação continuada e subsidiar uma proposta formativa. Como resultados parciais, é possível indicar uma formação profissional continuada, com oportunidade de atuação docente. Ao final deste trabalho, foi possível constatar a necessidade de formação continuada do profissional docente na área da beleza como diferencial competitivo no mercado, mas que não se limite a isso, ao contrário, transcenda e alcance uma educação crítica e transformadora.
\end{abstract}

Palavras-chave: Formação; Docência; Profissionalização; Estética e cosmética; Beleza.

\begin{abstract}
This article aims to analyze the process of professional training related to teaching in beauty centers and schools. To achieve this goal, a qualitative research was developed, which initially consisted of approaching concepts such as beauty and aesthetics pertaining to the professional field. In addition, professional training was addressed at different levels of education: basic and higher. For this, the exploratory bibliographical research was fundamental to provide subsidies in the elaboration of the theoretical framework of this work. It was assumed that for a solid education in the area of beauty, it is necessary to align the teaching positioning regarding the technical degree used or directed to the identification of the potential of each individual, respecting their positioning, experiences, particularities and applicability of related techniques to the services provided. Finally, it was also presented, under ethnographic guidance, from the formative experience of one of the signatories of this research as a student and as an instructor in the area of beauty, autobiographical reports to corroborate the need for continuing education and support a formative proposal. As partial results, it is possible to indicate continued professional training, with the opportunity for teaching. At the end of this work, it was possible to see the need for continuing education of professional teachers in the area of beauty as a competitive differential in the market, but that it is not limited to that, on the contrary, it transcends and reaches a critical and transforming education.
\end{abstract}

Keywords: Training; Teaching; Professionalization; Aesthetics and cosmetics; Beauty.

\section{Resumen}

Este artículo tiene como objetivo analizar el proceso de formación profesional relacionado con la docencia en centros y escuelas de estética. Para lograr este objetivo, se desarrolló una investigación cualitativa, que inicialmente consistió en abordar conceptos como la belleza y la estética pertenecientes al ámbito profesional. Además, se abordó la 
formación profesional en diferentes niveles educativos: básico y superior. Para ello, la investigación bibliográfica exploratoria fue fundamental para brindar subsidios en la elaboración del marco teórico de este trabajo. Partimos de la hipótesis de que para una formación sólida en el área de la belleza es necesario alinear el posicionamiento docente en cuanto al grado técnico utilizado o dirigido a la identificación de las potencialidades de cada individuo, respetando su posicionamiento, vivencias, particularidades y aplicabilidad de técnicas relacionadas a los servicios prestados. Finalmente, también se presentó, bajo orientación etnográfica, a partir de la experiencia formativa de uno de los firmantes de esta investigación como estudiante y como docente en el área de la belleza, informes autobiográficos para corroborar la necesidad de la educación continua y sustentar un propuesta formativa. Como resultados parciales, se puede señalar una formación profesional continuada, con oportunidad para la docencia. Al final de este trabajo, se pudo vislumbrar la necesidad de la formación continua del profesorado profesional en el área de la belleza como un diferencial competitivo en el mercado, pero que no se limita a que, por el contrario, trasciende. y alcanza una educación crítica y transformadora.

Palabras clave: Formación; Docencia; Profesionalización; Estética y cosmética; Belleza.

\section{Introdução}

No início do século XX, ainda não se cogitava, na legislação, uma formação pedagógica para o ensino das profissões. Em 1909, foi instituído um decreto para a criação das Escolas de Aprendizes Artífices, no qual constavam os deveres do professor que atuava nesse tipo de escola. Eram incluídos os cuidados com as ferramentas e os utensílios, assim como os apontamentos e os registros de frequência, além das normas de obediência ao diretor. No entanto, não havia, nesse decreto, nenhum artigo dedicado à formação docente. Por outro lado, algumas experiências foram registradas ao longo da história, tais como a existência de cursos para docentes nas escolas profissionais no Rio de Janeiro e em São Paulo (Martins, 2010; Queluz, 2010; Paulilo, 2017).

Parte-se do entendimento de que as mazelas do trajeto de formação do professor/formador dificultam o seu desenvolvimento, gerando obstáculos na promoção de sua qualificação técnica. Conforme Saviani (2003), os fatores socioeconômicos e suas desigualdades impõem aos filhos da classe trabalhadora, a iniciação em atividades que gerem fonte de renda familiar ou complementar. Devido esta imposição de ordem econômico-financeira, desde cedo, essa parcela da população renuncia à escolaridade e suas trilhas de aprendizagem. Assim, tornam-se mão de obra barata, por não possuir formação e oportunidades adequadas. Em alguns casos, podem até ser marginalizados por adicionarem fatores como famílias desestruturadas, violência doméstica, etnia raça/religião, gênero etc.

Ao longo dos anos, é notório que o processo tecnológico vem impactando diretamente a sociedade que, aos poucos, são impulsionadas para adaptações e inovações. Esse fenômeno gera limitação de mão de obra qualificada, provocando desemprego, acarretado pelo processo de automação. Desta forma, é exigido pelo mercado um posicionamento que busque adquirir novos conhecimentos em cursos profissionalizantes na educação básica ou qualificação técnica e superior.

Hoje, devido à complexidade do conhecimento tecnológico com o acelerado desenvolvimento de ferramentas, técnicas capazes de suprir as necessidades existentes, pode trazer à tona o espírito criativo para obter equipamento/utensílios/ferramenta adequados às demandas. Isto se faz por meio de protocolos, manipulações associadas a produtos/cosméticos extraídos de forma natural ou automatizado capaz de atender às diversas classes existentes em uma sociedade capitalista. Logo, essas práticas tornam a relação entre trabalho, ciência e tecnologia indissociáveis (Lima Filho, 2005).

Neste trabalho, entende-se os centros e as escolas de beleza como o espaço de formação inicial do profissional da área. O tema discutido neste texto é delimitado ao processo de formação profissional na área de beleza, algo que se desenvolve na educação básica, mas pode ser ampliado por estudos em nível superior. Neste sentido, busca-se responder a seguinte pergunta: Como está ocorrendo o processo de formação dos profissionais da área da beleza e estética no contexto atual? O percurso escolhido para o seu desenvolvimento pode sinalizar possíveis fragilidades na formação destes profissionais. Assim, cabe uma pesquisa no intuito de compreender as situações em que há uma limitação ou “descaso" com esta demanda que 
precisa de atenção, pois esses profissionais prestam serviços à sociedade e tem um relevante potencial de crescimento empreendedor, capaz gerar renda na área onde atuam.

Desta forma, parte-se da hipótese de que para uma formação sólida na área da beleza é preciso alinhar o posicionamento de ensino referente ao grau técnico utilizado ou direcionando sobre a identificação do potencial de cada indivíduo respeitando seu posicionamento, experiências, vivências, particularidades e aplicabilidade de técnicas referentes aos serviços prestados.

O objetivo geral desta pesquisa é analisar o processo de formação profissional relacionado à docência em centros e escolas de beleza. Para alcançar esse objetivo, foi pensado nos seguintes objetivos específicos, a saber: relacionar os conceitos de beleza e estética; discutir sobre o processo formativo do profissional da beleza, nos níveis médio e superior; narrar a trajetória de um processo formativo, por meio de memórias e relatos de vivências autobiográficos; e, por fim, apresentar uma proposta formativa, ou melhor, um caminho possível de ser trilhado para a formação deste profissional.

Esta pesquisa tem como justificativa pessoal, a imersão de um dos signatários da presente pesquisa no universo da beleza e estética, seja como aluno, instrutor ou profissional atuante na área. É possível dizer que também apresenta uma justificativa pedagógica, tendo em vista que a análise apresentada fomenta a formação continuada dos profissionais da área que têm uma função social relevante no bem-estar das pessoas. Além disso, o trabalho apresenta ainda uma justificativa acadêmica que é a necessidade de desenvolvimento de estudos na área, tendo em vista que carece de pesquisas. Por fim, também pode trazer uma justificativa político-social, pois a partir de uma formação crítica, o profissional da área de beleza também pode ressignificar a construção da ideia de beleza e estética rompendo com padrões impostos socialmente pela ordem do capital.

\section{Metodologia}

Para alcançar os objetivos propostos neste artigo, optou-se por uma pesquisa de natureza qualitativa, pois possibilita a leitura da realidade, entendendo, conforme Chizzotti (1995), que há uma relação dinâmica entre o mundo e o sujeito, ou seja, uma interdependência indissociável entre sujeito e objeto, não se limitando a apresentação de um rol de dados isolados. Inicialmente, foi necessário explorar as categorias fundamentais para o desenvolvimento deste trabalho, a saber: estética e beleza. Depois, também foi discutido sobre a formação do profissional na Educação Básica e Superior. Gil (1999) indica que, na fase exploratória, o objetivo principal é desenvolver, esclarecer e modificar conceitos e ideias, tendo em vista a formulação de problemas mais precisos ou hipóteses para estudos posteriores. Assim, um estudo baseado numa pesquisa bibliográfica é fundamental para a coleta das bases teóricas, no intuito de desenvolver um pensamento crítico em relação ao tema em tela. Segundo Lakatos e Marconi (1991), esse tipo de estudo possibilita o contato do investigador científico com um número significativo de informações, a exemplo de publicações avulsas, revistas, livros, jornais, monografias, artigos acadêmicos além de meios de mídia e audiovisuais.

Por fim, amparados por uma orientação etnográfica, a partir da constituição de narrativas em relatos autobiog ráficos, seguindo na esteira dos estudos de Mendes (2010), Ferreira Neto e Silva $(2019,2021)$ e Ferreira Neto (2020) foram apresentados fragmentos de uma trajetória formativa de Anderson de Oliveira Firmino (2020), signatário desta pesquisa, figurando como aluno e como instrutor na área da beleza. Desta forma, por meio de um relato autobiográfico, buscou-se registrar essas vivências desta trajetória para afirmar a necessidade de uma formação continuada e subsidiar uma proposta formativa. 


\section{Resultados e Discussão}

Para o desenvolvimento do tema central deste trabalho, esta seção foi subdividida em quatro partes, a saber: sobre o conceito de estética e beleza; a formação do profissional no nível Básico e Superior; fragmentos de uma trajetória formativa; e, por fim, uma proposta de ensino/formação.

\subsection{Sobre o conceito de estética e beleza}

O conceito de estética e beleza se adere por diversos níveis de conhecimentos e em outras áreas tais como: psicologia, filosofia, antropologia, dentre outras. Esta busca incessante do belo esteticamente, segundo Schubert (2009), é tão antiga quanto a existência da humanidade.

Dentro de um contexto histórico ao início dos tempos, entende-se que a beleza surge dentro de uma concepção do homem sobre a literatura, arte ou pintura. Vigarello (2006) assinala que, em busca de um corpo perfeito, os grandes pintores, dentro de seus ateliês, admiravam suas modelos, independentemente de sua origem, pela sua beleza. No fim do século XV, influenciado por um novo padrão, sofrendo mudanças conforme o tempo, o conceito de beleza tomou um novo posicionamento no século XVI, atraindo um novo olhar pela volumetria dos corpos sobre visão mimética, definindo melhor suas formas e espessuras. No século XVIII, há o uso de espartilho e de maquiagem em suas variações de cores, atribuindo em suas particularidades individuais com a proposta de especialidade pelos boticários ou perfumarias. Em meados do século XIX, a utilização de recursos estéticos, com fácil acesso à tecnologia dentro de produtos, acarretou uma busca de perfeição sobre o corpo. Nesse contexto, uma série de exercícios e regimes foram idealizados como um novo padrão de beleza e cada vez mais influenciados atualmente pelas mídias e grandes propostas de empresas que promovem um mercado em ascensão.

Atualmente, a busca incessante em procedimentos estéticos se tornou uma constante no fito de adquirir um novo formato/forma para enquadra-se na sociedade e firmar o "belo". Nesse cenário, cabe ao profissional esclarecer todos os benefícios, eficácia e necessidade em relação aos riscos, que podem comprometer a saúde, acarretando algum acompanhamento psicológico por conta de mudanças, muitas vezes, irreversíveis (Aguiar, 2006).

Suenaga et al. (2012), a partir de uma perspectiva kantiana, afirma que o belo está no campo da subjetividade, pois não pode atender as regras da objetividade para delimitar o seu conceito. Nesta ótica, todo juízo proveniente desta fonte é estético, ou seja, o seu fundamento determinante é o sujeito, pois está ancorado em um sentimento subjetivo e não propriamente em um conceito objetivo.

É notório que o conceito de estética e beleza se relacionam. Se na antiguidade havia uma objetividade ao definir esses conceitos, no qual a estética cuida do belo, hoje se percebe que estas categorias são mais fluidas. Assim, atendem às subjetividades, pois a existência é plural, não podendo haver apenas um parâmetro delimitador do entendimento de belo.

\subsection{A formação do profissional no nível básico e superior}

A formação do profissional da área de beleza e estética pode ocorrer em várias etapas do ensino, tanto em nível Básico como em Superior. Tal importância requer direcionamento no processo de formação para obter expertise na área e exercício da profissão. No fito de evitar possíveis riscos no manuseio de tecnologia e cosmética, protegendo o cliente e fazendo com que este tenha um adequado atendimento que garanta como resultado e qualidade de vida, sua satisfação, a Agência Nacional de Vigilância Sanitária - ANVISA, regulamenta, controla e fiscaliza todos os protocolos utilizados.

De acordo com a ANVISA:

[...] cosméticos, produtos de higiene e perfumaria são preparações constituídas por substâncias naturais ou sintéticas, de uso externo nas diversas partes do corpo humano', pele, sistema capilar, unhas, lábios, órgãos genitais externo, 
dentes e membranas mucosas da cavidade oral, com objetivo exclusivo ou principal de limpá-los, perfumá-los, alterar sua aparência e/ou corrigir odores corporais e/ou protegê-los ou mantê-los em bom estado (Resolução da Diretoria Colegiada - RDC n 211 , de 14 de julho de 2015).

É possível afirmar, com base em Halal (2012), que os profissionais na área de beleza e estética precisam adquirir o conhecimento apropriado acerca das químicas nos produtos usados ou as inúmeras reações químicas que acontecem no salão cotidianamente. Não estamos dizendo com isso que seja preciso um conhecimento aprofundado, mas é preciso conhecer, minimamente, as substâncias manipuladas para o desenvolvimento do trabalho. Nesta esteira, a cosmetologia é fundamental para o profissional desta área, pois esta é a ciência que trata da preparação, estocagem e aplicação de produtos cosméticos, bem como das regras que regem essas atividades, sejam elas de natureza física, química, biológica ou microbiológica (Paez, 2021).

Os processos envolvidos no desenvolvimento da profissão requer estudo, análise e compreensão no intuito de se tornar apto a exercer suas habilidades na prestação de serviços em estabelecimento ou ministrando aulas em estabelecimentos de formação salão escola, instituições profissionalizantes de nível básico ou superior respeitando, é claro, o nível e grau de instrução.

O processo de profissionalização está interligado e iniciado pelos níveis básico (profissionalizante e técnico) e superior. É possível inferir, a partir da leitura da Lei de Diretrizes e Bases da Educação Brasileira, que a Educação Profissional, a rigor, é uma modalidade de ensino da Educação Básica, que pode se dar a partir de Cursos Técnicos, de Formação Inicial e Continuada - FIC (qualificação) e de Formação de Docentes (Brasil, 1996).

Nesse processo formativo, é possível desenvolver nos alunos pensamentos mais críticos capazes de buscarem soluções. Segundo Gramsci (1982), ao tratar de uma "formação humanista", no nível equivalente ao Ensino Médio, afirma que esta fase de formação é decisiva, pois é nela que se desenvolve a criação de valores sobre autonomia, necessária para criação de caráter prático-produtivo, desenvolvendo métodos criativos buscando responsabilidades em prol do amadurecimento e postura profissional.

Conforme Gmelin (1848), o processo de estudo sobre composição química dentro dos produtos cosméticos remete ao conhecimento de básicos de química orgânica pois estuda os compostos de carbono, sendo utilizados nos mais simples umectantes aos complexos bioativos. Referência dos estudos onde esses conhecimentos se encaixam dependendo de sua complexidade, final de Ensino Médio e, posteriormente ou concomitantemente, no Ensino Técnico e, depois, no Superior aferindo competências necessárias dentro de laboratórios com experimentos (SENAC, 2014).

Segundo Rebello (2004), atualmente, a evolução cosmética está enraizada por estudos científicos, não apenas da área de atuação correlacionada à sua especialidade, mas principalmente pautada na biologia médico-dermatológica. Neste sentido, cabe uma investigação contínua. Dentro deste aspecto, identifica-se que o grau de instrução no repasse de informações por meio de certificação garante a qualidade na formação deste profissional.

Amparado em Marx e Engels (2004), é possível dizer que além de conhecimento técnico, também é preciso pensar em desenvolver a criticidade para que o profissional possa estar atento às demandas do mercado sem se entregar a modismos, observando a partir de uma visão crítica, do seu lugar de classe. Autores de base marxista, quando discutem a educação do tempo em que viveram, imersos em uma sociedade capitalista, admitem a possibilidade da profissionalização quando associada à educação intelectual, física e tecnológica, compreendendo-a como o germe da educação do futuro.

Assim, seria preciso pensar em uma educação igual para todas as classes. É preciso compreender que nesta sociedade de origem burguesa, com base no capital como forma de sociabilidade, a escola tem um papel reprodutor, mas, ao mesmo tempo, é o meio pelo qual se pode transformar a sociedade.

Algumas pessoas entendem, a partir do senso comum, que os profissionais da área de estética até mesmo nas escolas e centros de beleza, são meros aplicadores dos produtos, não se importando com os protocolos, meios de utilização e sim com o 
resultado e a finalidade. Grande parte da sociedade ainda enraizada no passado consideram a ideia de que os profissionais não têm instrução adequada, ainda com preconceitos referentes à raça, classe social, dentre outros. É notório que, no Brasil, o sistema de cotas foi instituído no intuito de diminuir as desigualdades socioeconômicas relacionadas a determinados grupos, como pessoas negras, indígenas e de baixa renda. Essa ação governamental teve o objetivo de democratizar o acesso ao ensino superior e aos cargos públicos. A formação se projeta como referencial sendo analisada por demanda dentro deste contexto educacional sobre as variáveis na instrução, dialogadas com cada especialidade no trabalho profissional do professor em prática docente.

A formação em meados dos anos 1990, atribuiu-se pela construção de conhecimento, baseando-se pelo que o aluno possui no decorrer de vivências ou experiências de vida, que agrega na busca incessante de paradigmas e de relevância social. Pimenta (1999, p. 19) aponta ainda para a busca de

[...] significação social da profissão; da revisão constante dos significados sociais da profissão; da revisão das tradições. Mas também da reafirmação das práticas consagradas culturalmente e que permanecem significativas. Práticas que resistem a inovações porque prenhes de saberes válidos às necessidades da realidade. Do confronto entre as teorias e as práticas, da análise sistemática das práticas à luz das teorias existentes, da construção de novas teorias.

Neste cenário, é notório o processo de formação continuada em diferentes níveis, nos quais há a necessidade de análise dos seus potenciais no aprimoramento de novas habilidades, desenvolvimentos de novas técnicas de ensino com referências tecnológicas em uma nova geração, pois a mesma com acesso facilitado sobre desenvolvimento e potencialidades nos resultados obtidos na busca do saber sendo executado e otimizado devido rapidez, eficácia e qualidade exigida.

Silva (2017), baseando-se em Clot (2010), identificou fragilidades enquanto sua formação na área da beleza, nas quais diretamente afeta os trabalhadores e sociedade em sua totalidade na oferta e prestação de seus serviços. Os docentes/formadores se encaixam dentro de uma necessidade de atualização continua referente às suas atividades.

Freire (1996) evoca uma educação da libertação e da autonomia, com o rompimento das imposições de origem colonial e opressora. Nessa perspectiva, é possível conceber um processo formativo na área de beleza que possa valorizar as personalidades e identidades dos grupos étnicos, no sentido de empoderamento dessas pessoas, saindo da invisibilidade ou subalternização. Ainda nesse sentido, o profissional que trilha uma formação com esse fundamento teórico é mais propenso a lutar por melhores condições de trabalho, assim como estimular outras lutas. Conforme Freire (1996), formar é muito mais do que apenas treinar o educando para que tenha um bom desempenho, ou seja, uma formação de base freiriana está em contraposição ao modelo capitalista de formação.

\subsection{Fragmentos de uma trajetória formativa}

Este trecho do trabalho é redigido na primeira pessoa do singular, tendo em vista se trata do registro em forma de relato autobiográfico do autor principal deste trabalho, Anderson de Oliveira Firmino (2020). Eis a narrativa...

Busco registrar, por meio de um relato autobiográfico, fragmentos de minhas vivências como professor, aluno e profissional no campo da beleza e estética, no intuito de refletir criticamente sobre minha própria trajetória e pensar como o profissional atual pode tornar esse percurso mais sólido, de modo a atender às demandas do mercado, sem deixar de pensar também nas demandas sociais.

Iniciei minha trajetória formativa como cabeleireiro profissional no processo de busca por uma profissão que me garantisse renda extra. Então, utilizando os meus conhecimentos prévios de forma paralela sobre atividade que exercia (trabalho/emprego), conseguia estes conhecimentos com atividades/whokshop/cursos de curta duração, no intuito de obter um retorno financeiro mais rápido, pois quando comparei e analisei meu trabalho celetista e prestação de serviços na área da 
beleza, vi o fator financeiro bem diferente, com o qual conseguia maior lucro em relação a um emprego formal, abrindo os olhos para empreender em meu próprio negócio futuramente.

A ideia de conseguir abrir/criar meu próprio negócio surgiu pelo desemprego do qual estava contratado em regime celetista e, com o dinheiro das contas, percebi que o momento e oportunidade estava ali. Então, comecei meu investimento no aspecto profissional. Primeiramente, comecei com o curso completo de cabeleireiro profissional, pois ainda não tinha uma base ou noção de mercado. Desta forma, a qualificação ajudou e foi o começo, pois me preparou para desenvolver novas técnicas, com as quais absorvi e vivenciei no curso e atendimentos prestados, as certificações necessárias que agregaram e facilitaram meu desenvolvimento para outras habilidades nichos de mercado. Visando o avanço tecnológico e cosméticos, vi a importância de formação contínua, pois tudo mudando ao tempo todo e não poderia parar. Quando se trata de beleza e estética é um campo que abrange muito estudo e percebi quando mergulhei a fundo nesta área, conhecimentos e caminhos/trilhas a seguir, principalmente quando se deseja uma especialidade.

O durante alguns anos, em busca de meu aperfeiçoamento, através de cursos e outras qualificações, aliadas a trabalhos e serviços prestados, consegui abrir meu salão e já pensando no período de festas do final de ano, no qual ocorre maior fluxo de cliente. Em setembro de 2015, iniciei de forma simples, mas com todo apreço, realizando/prestando os serviços de profissionais: cabeleireiro, barbeiro, designer de sobrancelhas, manicure/pedicure e depilação. Encontrei muitas dificuldades em tocar meu negócio sozinho. Devido não saber administrar meu empreendimento e sonho, vi a necessidade de investir nesta qualificação, permaneci aproximadamente um ano com este negócio. Com essa experiência, entendi que os cursos em sua grande maioria não repassam ou orientam quanto a gestão do negócio, apenas focam em técnicas e de como utilizar os produtos. Muitos profissionais têm os conhecimentos empíricos (baseado nos achismos), a administração/precificação é colocada em segundo ou terceiro plano, por "não acharem necessário" ou dizem que precisa ser feito, mas não ensina na prática. Muitos colegas que fiz e amigos de profissão sem formação (ensino fundamental, médio ou superior) por várias situações: família desestruturada, foram expulsos de casa por serem LGBTQIA+, etc., possuem muitas dificuldades neste aspecto ao qual fiz parte.

Em junho de 2016, recebi uma proposta de ministrar aulas em uma instituição e ensino profissionalizante, atuando no curso de cabeleireiro como instrutor, fiz o processo seletivo e identifiquei que nesta área existem muitos profissionais, habilidades necessárias que precisava desenvolver e experiências que, para mim, tudo estava sendo novo. Após a seleção, vi que as exigências na minha atuação como gestor (emprego anterior no regime CLT), pois sou formado em Tecnólogo em Marketing, deram-me uma base para conseguir a vaga e assim desenvolver o papel de instrutor. Houve uma identificação, pois filho de pais professores percebia que a condução de uma sala de aula requer mais do que habilidades técnicas da profissão e sim de entender as pessoas com cada particularidade e limitação trazendo esses fatores no processo evolutivo de tal importância no aprendizado.

Com o passar dos anos e todos os cursos/qualificações que adquiri em nível profissionalizante, nos quais tenho aperfeiçoamentos também em outros nichos de mercado, pois atuo como: cabeleireiro, barbeiro, maquiador, designer de sobrancelhas e cílios, fez com que trouxesse uma visão de querer algo maior e trabalhar com saúde e bem-estar dos clientes/consumidores/aluno. Em meio de situações vivenciadas, existem recursos dos quais podemos utilizar em meio a tratamentos, agregando qualidade de vida das pessoas, orientação médica quando necessário, direcionar o consumidor de forma assertiva por não saber de problemáticas existentes (saúde), a proposta de um atendimento humanizado trazendo a empatia ao próximo, não visando apenas de lucro e sim mobilizar socialmente esses profissionais em construção para perceberem que as pessoas em geral, ou público alvo/cliente/consumidor, possuem suas características peculiares. Como um profissional, desenvolvo múltiplas funções, abrangendo de forma integrada e significativa a importância deste conhecimento e não o limitando. 
Assim, dentro de minha trajetória, posso afirmar que a especialização em Estética e Cosmetologia agrega ao meu lado profissional a responsabilidade social, não apenas para o repasse de informações, mas também para orientação e formação de outras pessoas. Como instrutor, também sou um educador, um profissional da educação, que colaboro para formar opiniões, além de instruir de forma técnica e humanizada, avaliando o potencial de cada aluno, pois dentro de meus atendimentos, na área da beleza, ao executar uma avaliação, precisamos usar dos recursos cosméticos e tecnológicos em sua aplicabilidade, mediante protocolos, gerando uma segurança para o cliente e qualidade de forma segura e eficaz no desenvolvimento destas funções. Além desta qualificação técnica, necessária para o desenvolvimento de minha profissão, filio-me ao pensamento de Freire (1996) que compreende uma educação que esteja para além de formar o aluno para desenvolver funções, é preciso pensar uma formação humana que emancipe e pense criticamente.

\subsection{Uma proposta de ensino/formação}

Por fim, propõem-se, a partir do material coletado e do registro de fragmentos de vivência pessoal apresentado, uma proposta de caminho formativo para os profissionais na área da beleza e estética. Para se trabalhar com procedimentos estéticos e beleza requer uma formação contínua, na qual exista o estudo de novas tecnologias, tanto em equipamentos quanto cosméticos e sobre suas aplicabilidades, pois os profissionais em estudo trabalham com matéria-prima e trabalham o desenvolvimento delas de forma consciente. O público-alvo requer maiores cuidados, é fundamental respeitar as particularidades de cada indivíduo, limitações dentro dos processos utilizados para tais fins.

O processo de formação para o profissional da beleza pode ser iniciado por vários fatores e principalmente influenciados pelas mudanças: origem externas, internas, pessoais ou vínculos profissionais. Exemplo disto é a continuidade de ciclos gerações/herança/tradição familiar, padrões de vida, classe social, rentabilidade em busca de retorno financeiro mais rápido, independência financeira, empreendedorismo, sonhos etc. Então, cabe ao indivíduo identificar-se com as propostas apresentadas, para encaminhar e trazer o direcionamento sobre tal mudança, permitindo-se ao novo.

O fato é que é preciso analisar a situação de formação em vários aspectos, sob os quais a sociedade posiciona esse profissional em alguns grupos, classes condições financeiras (fragmento de classe), direcionando ou criando sua trilha de aprendizagem ou excluindo-a pela imensidão educacional. Para apresentar um diferencial no aprendizado de forma integrada, é necessário contribuir para que os conhecimentos prévios possam vir à tona. Isso possibilita o equilíbrio em prol de um padrão aceitável de acordo com a proposta utilizada. Essa trilha pode seguir pelos cursos profissionalizantes, técnico e superior.

Acredita-se, a partir do percurso formativo apresentado e embasado no referencial estudado, que seja preciso avaliar a capacidade de instrução e orientação do docente/formador nos cursos da área da beleza e estética com a proposta de agregar métodos e condutas avaliando os diferentes níveis de capacitação sobre os conhecimentos, temáticas e técnicas. Assim, o resultado de uma avaliação básica se prestaria ao docente/formador para traduzir detalhadamente os conhecimentos absorvidos pelos alunos, delimitando período de aprendizagem, por meio de exame. Conforme Vianna (2000), a avaliação procura sistematizar suas atividades, para, paulatinamente, criar uma estrutura que permita coletar diferentes tipos de informação, no intuito de possibilitar a verificação da aprendizagem e, consequentemente, tomar decisões para escolha de outras estratégias de aprendizagem.

A tríade professor/formador/instrutor alinhando a coordenação pedagógica e diretoria escolar idealiza conceitos, respeitando as limitações da instituição. Esta relação dialógica pode proporcionar o direcionamento para a escolha do que pode ser oferecido sobre conteúdos relevantes e condizentes na qualificação. Assim, é necessário entender o desenvolvimento de trilhas de aprendizado para a práxis profissionais, agregando um arsenal de conhecimento. 
É pressuposto básico que o docente da educação profissional é, essencialmente, um sujeito da reflexão e da pesquisa, aberto ao trabalho coletivo e à ação crítica e cooperativa, comprometido com sua atualização permanente na área de formação específica e pedagógica, que tem plena compreensão do mundo do trabalho e das redes de relações que envolvem as modalidades, níveis e instâncias educacionais, conhecimento da sua profissão, de suas técnicas, bases tecnológicas e valores do trabalho, bem como dos limites e possibilidades do trabalho docente que realiza e precisa realizar (Machado, 2008, p. 17).

No contexto hodierno, no qual é vivenciada a pandemia de COVID-19, é preciso seguir o caminho das tecnologias e inovar em sua experiência formativa. Nesta esteira, pode-se apontar para o ensino remoto como saída momentânea ou, ainda, o ensino híbrido, no qual as ferramentas tecnológicas possam fomentar uma formação sem interrupções. Ferreira Neto et al. (2020) indica o trabalho com aulas remotas por meio de planejamento de projetos. Batista et al. (2021) assinala a necessidade de reorganização do processo de ensino-aprendizagem diante do cenário, apontando também para os projetos. As experiências na trajetória e formação profissional, tornam-nos eternos pesquisadores, pois tudo muda, o tempo todo, e, nesse percurso, é preciso entender seu funcionamento, reinventar-se como profissional, não se entregar a comodismos. É necessário sempre aprender a aprender.

\section{Considerações Finais}

Ao final deste trabalho, é possível afirmar que os profissionais da área da beleza e estética precisam de uma formação continuada, pois uma formação profissional a partir de um curso profissionalizante não é suficiente para suprir as necessidades do mercado de consumo. Além disso, as demandas sociais pedem um profissional mais sensível com as lutas e identidades silenciadas, em outras palavras, transcenda as necessidades de mercado e alcance uma educação crítica e transformadora.

Foi possível confirmar a hipótese apresentada, ou seja, é preciso desenvolver uma formação sólida para atuação na área da beleza, alinhando o posicionamento de ensino referente ao grau técnico utilizado ou direcionando para a identificação do potencial de cada indivíduo, não perdendo de vista o respeito ao seu posicionamento, experiências, vivências, particularidades e aplicabilidade de técnicas referente aos serviços realizados.

Dessa forma, o objetivo de analisar o processo de formação profissional relacionado à docência em escolas e centros de beleza foi atingido. Inicialmente, foi discutido sobre estética e beleza, angariando fundamentação teórica para a execução de um trabalho com criticidade, que não se limite às exigências do mercado, mas que também possa atuar em sua transformação. Nesse sentido, também foi abordado a formação deste profissional no Ensino Básico assim como a possibilidade de seguir no Ensino Superior. Por fim, a partir de imersão pessoal como aluno, profissional da beleza e instrutor, aliado a estudos teóricos foi possível ampliar compreensão da atuação deste profissional no mercado de trabalho, apontando para a continuidade da pesquisa, buscando um maior aprofundamento em outro momento.

\section{Agradecimentos}

Os agradecimentos são direcionados à Faculdade Venda Nova do Imigrante, na pessoa da Professora Doutora Ana Paula Rodrigues pela orientação do Trabalho de Conclusão do Curso de Especialização em Estética e Cosmetologia. E ainda ao Professor Mestre José Olímpio Ferreira Neto pela coorientação e coautoria neste trabalho.

\section{Referências}

Aguiar, T. (2006). Personal stylist: guia para consultores de Imagem. (4a ed.), Senac.

Agência Nacional de Vigilância Sanitária. (2015). Resolução da Diretoria Colegiada - RDC no 211, de 14 de julho de 2015 . Estabelece a Definição e a Classificação de Produtos de Higiene Pessoal, Cosméticos e Perfumes, conforme Anexo I e II desta Resolução e dá outras definições. D.O.U. de 18 de julho de 2005. http://www.cvs.saude.sp.gov.br/zip/U_RDC-ANVISA-211_140705.pdf 
Batista, C. S. M. ., Gaspar, G. T. T. ., Junio, S. dos S. ., Oliveira, V. A. de ., \& Silva, A. M. da. (2021). Ensino remoto em um curso técnico presencial: Reflexos de um projeto interdisciplinar no contexto da pandemia. Research, Society and Development, 10(7), e54110716695. https://doi.org/10.33448/rsdv10i7.16695

Brasil. (1996). Lei $n^{o}$ 9.394, de 20 de dezembro de 1996. Estabelece as diretrizes e bases da educação nacional. D.O.U. de 23 de dezembro de 1996. http://www.planalto.gov.br/ccivil_03/leis/19394.htm

Chizzoti, A. (1995). Pesquisas em ciências humanas e sociais. Cortez.

Clot, Y. (2010). Trabalho e Poder de Agir. Fabrefactum.

Ferreira Neto, J. O. (2020). O legado da Associação Terreiro para a capoeira do Ceará. Ensino Em Perspectivas, 1(1), 1-14. https://revistas.uece.br/index.php/ensinoemperspectivas/article/view/4533

Ferreira Neto, J. O., Vasconcelos, A. P. M. F. ., Souza, A. M. da C. ., \& Paim, I. de M. . (2020). A aplicação do Project Model Canvas para o planejamento de um projeto educacional com aulas remotas no período de distanciamento social. Research, Society and Development, 9(12), e16691210928. https://doi.org/10.33448/rsd-v9i12.10928

Ferreira Neto, J. O., \& da Silva, R. C. (2019). Mestre Chitãozinho e a formação dos capoeiristas no Projeto ABC do João XXIII. Práticas Educativas, Memórias E Oralidades - Rev. Pemo, 1(1), 1-14. https://doi.org/10.47149/pemo.v1i1.3518

Firmino, A. de O. (2020). Relatos autobiográficos de uma trajetória formativa na área de beleza. Fortaleza.

Freire, P. (1996). Pedagogia da Autonomia: saberes necessários à prática educativa. Paz e Terra.

Gil, A. C. (2008). Como elaborar projetos de pesquisa. Atlas.

Gramsci, A. (1982). Os intelectuais e a organização da cultura. (4a ed.), Civilização Brasileira.

Halal, J. (2012). Tricologia e a química cosmética capilar. Cengage Learning.

Lakatos, E. M., \& Marconi, M. A. (1991). Fundamentos de metodologia Científica. Atlas.

Lima Filho, D. L. (2005). A universidade tecnológica e sua relação com o ensino médio e a educação superior: discutindo a identidade e o futuro dos CEFETs. Perspectiva - Revista do Centro de Ciências da Educação da UFSC, 23, 349-380.

Machado, L. (2008). Diferenciais inovadores na formação de professores para a educação profissional. Revista Brasileira da Educação Profissional e Tecnológica, Ministério da Educação, Secretaria de Educação Profissional e Tecnológica, 1, MEC, SETEC.

Martins, L. M. (2010). O legado do século XX para a formação de professores. In: MARTINS, L. \& DUARTE, N. (Orgs.). Formação de professores: limites contemporâneos e alternativas necessárias [online]. São Paulo: Editora UNESP; São Paulo: Cultura Acadêmica. http://books.scielo.org/id/ysnm8/pdf/martins9788579831034-02.pdf

Marx, K.. \& Engels, F. (2004). Manifesto do Partido Comunista. Martin Claret.

Mendes, E. G. (2010). A etnografia como trilha metodológica. In: VASCONCELOS, J. G. et al. (Org.). História da Educação: nas trilhas da pesquisa. Fortaleza: UFC. p. 192-205.

Paulilo, A. L. (2017). Um capítulo da História da Formação e da Profissão Docente no Brasil: O Instituto de Educação do Distrito Federal e sua Historiografia. Educ. Soc., 38, .117-132

Paez, L. (2021). Cosmetologia e o âmbito da legislação. Blog IBECO Faculdade. https://ibeco.com.br/cosmetologia-e-o-ambito-dalegislacao/\#: :text=Cosmetologia\%20\%C3\%A9\%20a\%20ci\%C3\%AAncia\%20que,\%2C\%20qu\%C3\%ADmica\%2C\%20biol\%C3\%B3gica\%20ou\%20microbi ol\%C3\%B3gica

Pimenta, S.G. (1999). Formação de professores: Identidade e saberes da docência. In: PIMENTA, S.G. (Org.) Saberes pedagógicos e atividade docente. São Paulo: Cortez.

Silva, R. C. da, \& Ferreira Neto, J. O. (2021). O protagonismo do Grupo Senzala na capoeira de Fortaleza e Teresina (1980-1990). Ensino Em Perspectivas, 2(1), 1-14. https://revistas.uece.br/index.php/ensinoemperspectivas/article/view/4551

Queluz, G. L. (2010). Escola de Aprendizes e Artífices do Paraná. Tecnol. \& Hum

Rebello, T. (2004). Guia de Produtos Cosméticos / Editora Senac São Paulo.

Saviani, D. (2003). A nova lei da educação: LDB, limite, trajetória e perspectivas. (8a ed.), Autores Associados.

Schubert, C. (2009). A construção do conceito estético Ocidental e sua implicação na formação valorativa e no processo educacional. In: Divisão Temática Interface Comunicativas do X Congresso de Ciências da Comunicação na Região Sul. Blumenal. http://www.intercom.org.br/papers/regionais/sul2009/resumos/R16-1303-1.pdf 
Research, Society and Development, v. 10, n. 9, e29910918181, 2021

(CC BY 4.0) | ISSN 2525-3409 | DOI: http://dx.doi.org/10.33448/rsd-v10i9.18181

SENAC. DR. CE. (2014). Cosmetologia Aplicada: à coloração e descoloração. / SENAC.CE.; ilustrações de Eli Barbosa (3a ed.), Editora Senac Ceará. (Coleção Segmento da Beleza) 84p.

Silva, R. N. D. (2017). A Química nos salões de beleza: Formação do profissional cabeleireiro. (Trabalho de Conclusão de Curso), Curso de Graduação em Química - Licenciatura, da Universidade Federal da Paraíba. p. 40.

Suenaga, C., Lisboa, D. C., Silva, M. S. de, \& Paula, V. B de. (2012). Conceito, beleza e contemporaneidade: fragmentos históricos no decorrer da evolução estética. (artigo) Curso de Especialização em Estética Facial e Corporal. Universidade do Vale do Itajaí. http://siaibib01.univali.br/pdf/Camila\%20Suenaga,\%20Daiane\%20Lisboa.pdf

Vianna, H. M. (2000). Avaliação Educacional: teoria, planejamento, modelos, IBRASA.

Vigarello, G. (2006). História da Beleza: o corpo e a arte de se embelezar, do Renascimento aos dias de hoje. Ediouro. 